\title{
Dr Francis Ramsbotham (1801-1868) and obstetric practice in London
}

\author{
Peter M Dunn
}

Francis Ramsbotham was born in Richmond in 1801. His father, John Ramsbotham, MD, was lecturer in obstetric medicine at the London Hospital. Francis was educated at St Paul's School and then apprenticed to a druggist in Cheapside. In 1818 he studied medicine first at the London Hospital and then in Edinburgh where he graduated MD in 1822 . His first move was to join his father in practice and to assist him with his lectures. In 1925 he was appointed physician to the Royal Maternity Charity and the Tower Hamlets and Eastern Dispensaries. The following year he gained the MRCP (F. 1844) and set up in practice on his own account in the east end of London.

That year, 1826, he helped to found and became honorary secretary to the Obstetric Society of London, the first aim of which was to place obstetric medicine on a more respectable footing than hitherto, by inducing the College of Physicians of London to abrogate its bye-law which precluded practitioners in midwifery from the fellowship; and by requiring the College of Surgeons and the Society of Apothecaries to make obstetrics a subject of undergraduate study and examination. The Royal College of Physicians' initial response was that obstetrics was 'an art foreign to the habits of gentlemen of enlarged academical education', but with the help of Sir John Peel at the Home Office, his aims were achieved within a few years.

In 1853 Francis Ramsbotham was appointed as first obstetric physician and lecturer in obstetrics and forensic medicine to the London Hospital. He published a number of obstetric articles but as an author he is chiefly known for his text on The Principles and Practice of Obstetric Medicine and Surgery, dedicated to his father, and first published in 1841. With 732 pages, it was beautifully illustrated with 90 plates by William Bagg. The extracts that follow are taken from the second edition which appeared in $1844 .^{1}$

Department of Perinatal Medicine and Child Health, University of Bristol, Southmead Hospital, Bristol BS10 5NB P M Dunn

Correspondence to: Professor P M Dunn.

\section{On the doctor's responsibilities during normal labour:}

'Generally, no active assistance is necessary, until after the birth of the child; all that is required of the attendant being that he should remain an observant, though unofficious, spectator of the process - ready to

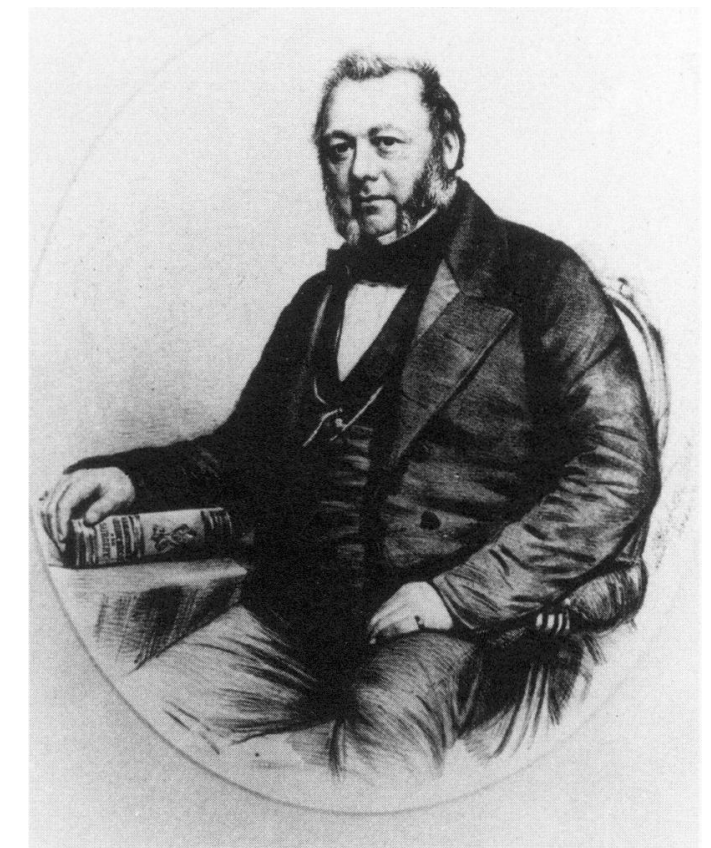

Dr Francis Ramsbotham, 1801-1868.

exert himself, with promptitude and energy, on the first accession of any alarming symptom; but equally, or more, ready to allow the changes necessary for the completion of Nature's object to proceed, uninterrupted by any meddlesome interference ... The only persons whom I would willingly admit are the nurse and some female married friend - the mother, or near relation or an intimate acquaintance - to act as confidant to the sufferer ... from whom she may receive those numberless comforts and sustaining consolations of which she stands eminently in need'.

On rickets and deformation of the pelvis:

'There are two diseases particularly, through which the pelvis suffers considerable deterioration in size, rickets a disorder of childhood, and mollities ossium, one of adult age ... the bones yield like softened wax; the regularity and beauty of the pelvic form is destroyed ... distortions of the pelvis were not known to the Greeks and Latins ... Nor can we be surprised at this; for rickets was first described by Glisson ... The habits of the ancients, indeed, were not favourable to the production of this formidable affection; their poorer 
population was mostly engaged in agricultural, or mechanical - not in what may properly in this age be termed manufacturing - pursuits; which latter, of all occupations, most fosters the rickety predisposition'.

\section{On lingering labour and maternal posture:}

'We may sometimes also succeed in rendering the uterine contractions stronger and more efficient by changing the patient's position, particularly from the recumbent to the upright posture; and as this is a very simple means, as it is often useful, and as the change brings her great relief, she may be advised to sit, stand, or walk, as her own inclination dictates. The effect is most probably produced by the gravitation of the head upon the os uteri'.

\section{On the liquor amnii:}

'Its real use appears to be, to defend the young embryo, in the early weeks of pregnancy, from the pressure of the uterine parietes, which must otherwise have annihilated it; and this is the reason why it then exists in such large proportionate quantity; - to protect the vessels of the funis and placenta in the latter months from a degree of compression which would have impeded the regular flow of blood through them; - and to allow free motion to the limbs of the foetus, so as to prevent them being cramped or distorted ... Besides these advantages, we find it performing a most important service in labour, when it conduces so essentially to the formation of the soft wedge-like bag. Its value does not cease even on the rupture of the membranes; for it assists in lubricating the vagina and external parts, and by this means prepares them for the more easy passage of the child'.

\section{On rupturing the membranes:}

'I must repeat the caution previously given against unnecessarily rupturing the membranes during the first stage of labour. It has of late become very much the practice to evacuate the liquor amnii in all cases where the uterus is acting feebly; and some instances have come under my own observation, in which not only has this act disappointed the intention of the operator, but been followed, after the lapse of some time, by such symptoms as required that the labour should be terminated instrumentally'.

Among 35743 deliveries supervised by Ramsbotham between 1828 and 1843 the incidence of complications (rates per 1000) were: accidental haemorrhage $3 \cdot 3$; placenta praevia $1 \cdot 1$; eclampsia 0.9 ; ruptured uterus $0 \cdot 2$; breech presentation $26 \cdot 1$. Among the obstetric interventions there were: induction of labour 6.0 ; forceps delivery 1.4 ; craniotomy $1 \cdot 1$; manual removal of placenta $5 \cdot 8$. The stillbirth rate for the series was 63 and the maternal mortality rate 4.6 (166 deaths): 40 were due to nonobstetric causes such as tuberculosis, typhus, and cholera. Puerperal sepsis accounted for only 30 deaths $(0 \cdot 8 / 1000)$ and eclampsia for just two. There were nine deaths following craniotomy or forceps delivery. Haemorrhage was responsible for 56 deaths $(1 \cdot 6 / 1000)$. His discussion of this major problem includes manual removal of the placenta, kneading the uterus, applying cold water or ice, the use of ergot and aortic compression. Two further aspects discussed were:

\section{On postpartum haemorrhage and suckling:}

'Dr Rigby thinks the application of the child to the mother's breast the most efficacious means of procuring uterine contraction in this species of haemorrhage. He grounds his opinions upon the sympathy which exists between the two organs, and the known fact of the action of sucking very generally inducing after-pains. If the trial can be made, without disturbing the patient much, I see no objection to its adoption'.

\section{On transfusion for postpartum \\ haemorrhage:}

'Our last resource is the transfusion of blood into the system of the dying patient ... To Dr Blundell is due the merit of having restored the practice ... But transfusion can be of little use, unless contraction has taken place in the uterine parietes ... I shall merely describe the readiest mode of performing the operation by a common syringe. The instrument should be of brass, tinned inside, capable of containing between two and three ounces, perfectly air-tight, and free from oil. One or two persons - males in preference to females, from their less liability to faint - being in readiness to supply the blood, one of the patient's veins at the bend on the elbow must be laid bare to the extent of an inch, and divested of its cellular web; an aperture must then be made into it rather more than a line in length. The blood must be drawn from one of the bystanders in a full stream about three ounces must be received into a conical cup or tumbler, and absorbed as soon as it is collected: the nozzle of the syringe must be raised perpendicularly, and the piston slowly propelled upwards, to expel any air that might have passed into the instrument: its point must afterwards be inserted into the aperture formed in the vein, and the blood slowly propelled towards the heart ... We may inject a second, third, and fourth syringe full, deliberately watching, between each, the effect produced'.

Ramsbotham married Mary, daughter of Henry Lindsay of Perth, and they had two sons. As an obstetrician he was very highly regarded and at various times filled the offices of president of the Harveian and Hunterian 
Societies and of vice-president of the Pathological Society. He was on very friendly terms with James Y Simpson of Edinburgh who held him in the highest professional esteem, even though Ramsbotham was reluctant for some years to promote the use of anaesthetics in uncomplicated labour. As he stated '... before anaesthetics can be introduced for the relief of ordinary pains of childbirth it must be proved incontestably that they are invariably safe both to the mother and her infant'. However, a decade later in 1867 he dedicated the fifth edition of his text to Simpson whose 'successful efforts to alleviate human suffering have rendered his name famous throughout the world'. In 1863 ill health forced him to retire and he went to live in the country. Five years later in 1868 he died in Perth at the age of 67.

1 Ramsbotham FH. The Principles and Practice of Obstetric Medicine and Surgery in Reference to the Process of Parturition. 2nd Edn. London: J Churchill, 1844. 